\title{
Research Article \\ The Impact of the HMCFRP Ratio on the Strengthening of Steel Composite I-Beams
}

\author{
E. Agcakoca and M. Aktas \\ Faculty of Engineering, Department of Civil Engineering, Sakarya University, Sakarya, Turkey \\ Correspondence should be addressed to M. Aktas, muharrema@sakarya.edu.tr
}

Received 5 October 2012; Accepted 23 October 2012

Academic Editor: Carlo Cattani

Copyright (C) 2012 E. Agcakoca and M. Aktas. This is an open access article distributed under the Creative Commons Attribution License, which permits unrestricted use, distribution, and reproduction in any medium, provided the original work is properly cited.

Carbon fiber-reinforced polymer materials have become popular in the construction industry during the last decade for their ability to strengthen and retrofit concrete structures. The recent availability of high-modulus carbon fiber-reinforced polymer strips (HMCFRP) has opened up the possibility of using this material in strengthening steel structures as well. The strips can be used in steel bridge girders and structures that are at risk of corrosion-induced cross-sectional losses, structural deterioration from aging, or changes in function. In this study, a set of bending experiments was performed on three types of steel beams reinforced with HMCFRP. The results were used to enhance a nonlinear finite element model built with ABAQUS software. The accuracy of the mathematical models for HMCFRP, epoxy, and steel profiles was compared with the experimental results, and the ability of HMCFRP to continue carrying load from the steel beams during rupture and postrupture scenarios was observed using numerical analysis. Using these verified finite element models, a parametric analysis was performed on the HMCFRP failure modes and the quantity to be used with IPE profile steel beams. The maximum amount of HMCFRP needed for strengthening was determined, and an upper limit for its use was calculated to avoid any debonding failure of the fiber material.

\section{Introduction}

Steel structural elements may require strengthening due to changes in functionality, increases in load-bearing capacity due to heavier traffic loads and corrosion occurring over time. The replacement of such elements and the installation of additional layer sections are typically proposed and applied in practice to solve these problems. However, these proposed solutions are problematic due to the increase in traffic delays they incur for bridge repairs and their cost inefficiencies [1]. Carbon fiber-reinforced polymer (CFRP) materials are heavily used in civil engineering, especially for repairing and strengthening concrete structural elements [25]. Such material was not usually preferred for steel structural repairs and strengthening due 
to its low elasticity modulus, but it is now being used in steel structural elements with the emergence of high-modulus carbon fiber-reinforced polymer (HMCFRP). The properties of CFRP, including corrosion resistivity, low weight, and prevention of postfatigue cracks, are the reason for this implementation [6-8]. A number of research studies exist on strengthening steel structures with HMCFRP, including studies on the CFRP end dimensions that will bond to steel most effectively $[9,10]$, extension lengths $[11,12]$, the impact of its thickness on its load-carrying capacity [8,13], and its use in welded joints [14, 15]. It was concluded that the most important issues remaining in the application of fiber materials to steel and concrete structures are bonding and development length. Aktas et al. [16] studied the impact of development length on load capacity and failure modes and determined the minimum development lengths to avoid debonding of HMCFRP. Other research also exists on the fatigue behavior of strengthened steel beams [7, 10]. Addressing the mechanical properties of fiber composites is essential in numerical modeling. The amount of volume fraction of fibers in composite matrix plays an important role for ignoring inhomogeneity [17].

The experiments found in the literature survey are limited and do not include a broad parametric study. Questions remain about whether there is an upper limit to the quantity of CFRP material that can be used in these scenarios, whether there is a relationship between an increase in load-carrying capacity and the use of HMCFRP and whether CFRP debonding occurs at epoxy interfaces such as in concrete structures. The goal of this study was to answer these questions as they apply to BA-composite IPE steel profiles strengthened with HMCFRP. Parametric studies were conducted using the nonlinear finite element method, and the developed finite element model was verified with three different experiments.

\section{Testing and Numerical Verification}

A two-step experiment was performed in this part of the study. In the first step, a steel Ibeam specimen was constructed and tested that matched the load-carrying capacity of a concrete composite steel I-beam. The concrete slab components were replaced by their steel counterparts and used for further studies, avoiding problems associated with manufacturing concrete parts and issues with numerical modeling during this parametric study on concrete composite I-beams. The load deflection behavior from the bending experiment validating this assumption is shown in Figure 1(a). Based on the similarity of the results, we continued to use the beam structure with a steel plate in Figure 1(c) in the rest of the study instead of the reinforced concrete composite I-beam shown in Figure 1(b). The second step consisted of strengthening experiments.

\subsection{Verification Experiments: Strengthened Beam}

Three identical steel composite beam plates were identically prepared and strengthened with HMCFRP to verify and test their nonlinear finite element model components. HMCFRP with dimensions of $1.4 \times 50 \times 2400 \mathrm{~mm}$ was bonded to steel tension flange with epoxy material. Prior to bonding, the bottom flanges were mechanically cleaned of dust and dirt. The epoxy was carefully prepared at the rate recommended by its manufacturer and applied directly to the bottom flange, creating a very thin layer. The HM-CFRP was then clamped on the epoxy with wooden clamps. After the manufacturer's recommended time had passed, the specimens were ready for bending experiments. 


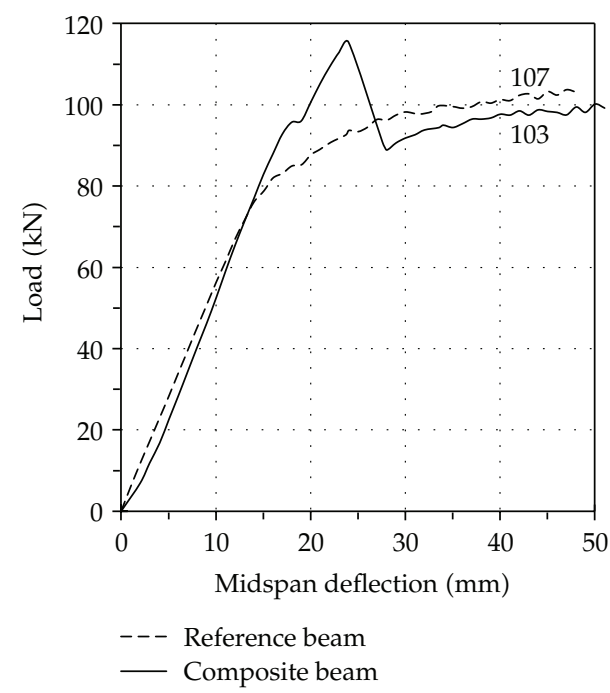

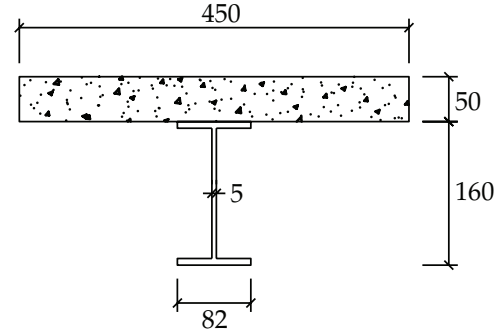

(b) Reinforced concrete composite I-beam (in $\mathrm{mm}$ )

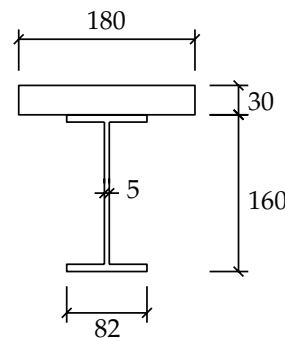

(c) Reference beam with steel plate instead of RC slap (in $\mathrm{mm}$ )

(a) Load-Midspan deflection

Figure 1: Comparison of beams with a reinforced concrete slab and a steel plate slab.

The beam specimens had a length of 3,000 $\mathrm{mm}$, and the distance between the supports was $2,900 \mathrm{~mm}$. The distance between the loading point and the end of the HM-CFRP material was $1,050 \mathrm{~mm}$, the distance between loading points was $800 \mathrm{~mm}$, and the load was applied using a $400 \mathrm{kN}$ piston. A $200 \times 200 \times 1000 \mathrm{~mm}$ spreader beam was used to apply equal loads to all of the beam's loading points. Two $20 \times 30 \times 900 \mathrm{~mm}$ steel bars were utilized to ensure load transfer from the spreader to the beam. Rubber pads were used to prevent the bars from causing damage to the specimen, and three displacement meters were employed at midspan and on the bottom flange where loads were applied to measure displacements. The test setup is presented graphically in Figure 2(a). A four-point load test layout that provided a fixed moment was applied to observe the strengthened beam's bending behavior.

The load deflection figures for the three strengthened beams and the unstrengthened reference beam are shown in Figure 2(b). To clearly illustrate the behavior of the structural elements, we define four regions ( $a, b, c$, and d) in the figures: (a) corresponds to the steel yield, (b) corresponds to the start of HMCFRP rupture, (c) shows loading of the steel without HMCFRP, and (d) shows the conclusion of the experiment. The added load-carrying capacity due to HMCFRP installation is an average of $39 \%$.

\subsection{Numerical Verification}

This section discusses the steps involved in nonlinear finite element modeling. Instead of costly lab experiments, nonlinear finite element models can be used to obtain approximate results with numerical experiments. However, the accuracy of the results may depend on the type of finite elements, material mathematical models, interface models and mesh densities used. The finite element model in this study was continuously improved until its results matched the actual experimental results. 


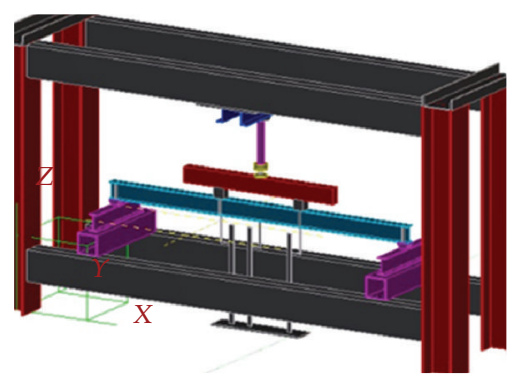

(a)

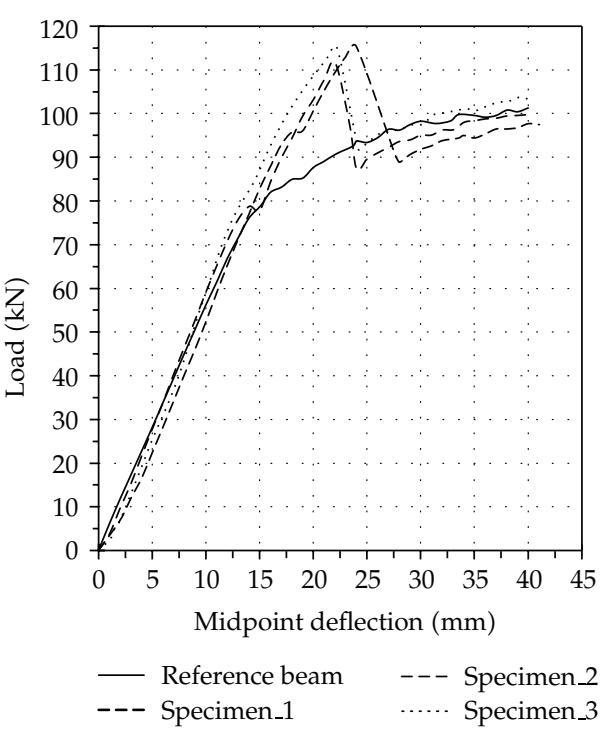

(b)

Figure 2: Test setup and results for strengthened beams.

Table 1: Mechanical properties of the specimen.

\begin{tabular}{|c|c|c|c|c|c|c|c|c|}
\hline \multicolumn{2}{|l|}{ HMCFRP } & \multicolumn{3}{|c|}{ Steel (I-beam) } & \multicolumn{2}{|l|}{ Steel plate } & \multicolumn{2}{|l|}{ Epoxy } \\
\hline Ult. strength $(\mathrm{MPa})$ & 1200 & Flange & $\begin{array}{l}\text { Yield strength } \\
(\mathrm{MPa})\end{array}$ & 275 & $\begin{array}{l}\text { Yield strength } \\
(\mathrm{MPa})\end{array}$ & 255 & $\begin{array}{l}\mathrm{G}, \text { modulus } \\
(\mathrm{GPa})\end{array}$ & 10720 \\
\hline E. modulus (GPa) & 440 & & $\begin{array}{l}\text { E. modulus } \\
(\mathrm{GPa})\end{array}$ & 179 & $\begin{array}{l}\text { E. modulus } \\
(\mathrm{GPa})\end{array}$ & 210 & $\begin{array}{l}\text { E. modulus } \\
(\mathrm{GPa})\end{array}$ & 29770 \\
\hline Width (mm) & 50 & Web & $\begin{array}{l}\text { Yield strength } \\
(\mathrm{MPa})\end{array}$ & 265 & & & $\begin{array}{l}\text { Nom. stress } \\
(\mathrm{MPa})\end{array}$ & 25 \\
\hline Thickness (mm) & 1.4 & & $\begin{array}{l}\text { E. modulus } \\
(\mathrm{GPa})\end{array}$ & 161 & & & & \\
\hline $\begin{array}{l}\text { Ult. long strain } \\
(\mathrm{mm} / \mathrm{mm})\end{array}$ & $0.2-0.3 \%$ & & Poisson's ratio & 0.3 & & & & \\
\hline
\end{tabular}

ABAQUS-Explicit software was used for the numerical analysis. Numerical difficulties arise when solving nonlinear problems in the implicit finite element method since the iterative approach which needs to achieve convergence to enforce equilibrium may fail in highly nonlinear problems. The nonlinearities in the material and geometries were accounted for in the analysis, and the nonlinear finite element model was derived by considering sensitive mesh dependency, using reduced integration in its formulation. This reduced computing time and minimized potential inaccuracies. The mechanical properties of the steel, epoxy, and HMCFRP used in the numerical model were experimentally measured and are provided in Table 1. The finite element types used in the numerical modeling and mathematical models from the analysis are listed in Table 2.

The steel components were modeled using mathematical models of an elastoplastic material (Table 2(a)). Work hardening of the steel was not taken into account. The Von Mises yield criterion was chosen as the failure of the steel. Based on the satisfactory accuracy of the finite element model for 4-node shell element shown in a study conducted by Aktas et al. [18], 
Table 2: Finite element properties of the specimen.

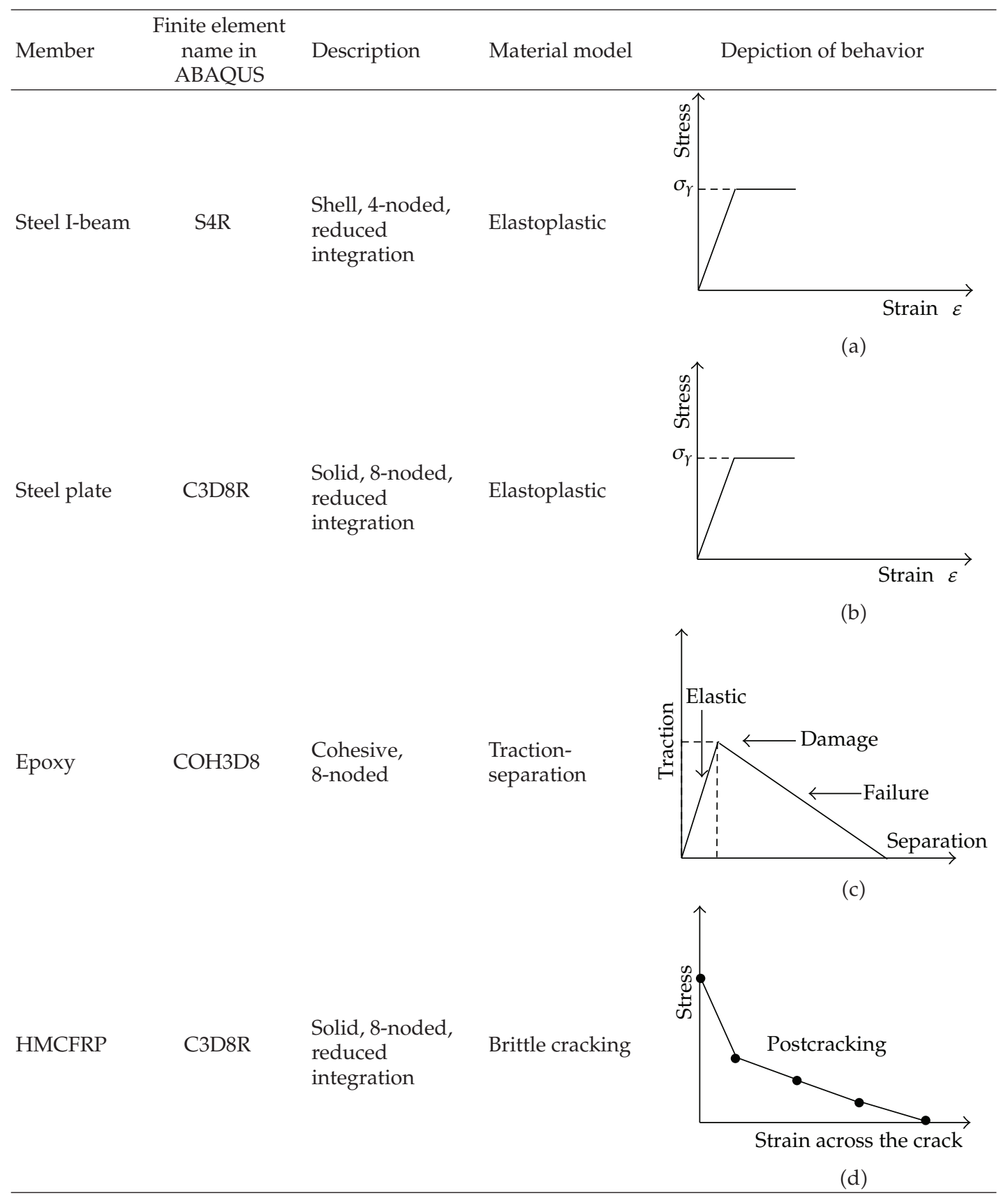

this paper also used a 4-node shell element in constructing I-beam. Because the steel plate being substituted for reinforced concrete had minor deformations, it was modeled as a solid 8-node element (Table 2(b)).

It is very important to have accurate and robust models for the epoxy material named as a cohesive layer in the analysis because the epoxy provides the medium for stress transfer 
between the steel and HMCFRP. It was modeled as a solid 8-node cohesive layer element and defined with a traction-separation mathematical model because it creates only a very thin layer and has a separation failure mode (Table 2(c)). In other words, the behavior of the epoxy defined as cohesive material was defined with a progressive damage and failure definition. Damage initiation of the epoxy occurs when the relationship shown in (2.1) is satisfied, where the tensile stress perpendicular to surface of the element is $t_{n}$ and that parallel to the surface is $t_{s}$ and $t_{t}$, and their maximum values are $t_{n}^{0}, t_{s}^{0}$, and $t_{t}^{0}$, respectively. Consider

$$
\left\{\frac{t_{n}}{t_{n}^{0}}\right\}^{2}+\left\{\frac{t_{s}}{t_{s}^{0}}\right\}^{2}+\left\{\frac{t_{t}}{t_{t}^{0}}\right\}^{2}=1
$$

Equations (2.2) are used in damage evolution behavior. These equations show the $\overline{t_{n}}$, $\overline{t_{s}}$, and $\overline{t_{t}}$ tensile strengths calculated from the elastic behavior of the material. $D$ is a scalar between 0 and 1 and is used as the damage parameter. The behavior between the maximum value and zero-tensile stress rupture moment is modeled linearly as follows:

$$
\begin{aligned}
& t_{n}=(1-D) \overline{t_{n}} \\
& t_{s}=(1-D) \overline{t_{s}} \\
& t_{t}=(1-D) \overline{t_{t}} .
\end{aligned}
$$

Epoxy layer which is modeled by employing cohesive elements is tied to the neighboring surfaces both on steel bottom flange and HM-CFRP top surface. Thus, the degree of freedom at the intersecting nodes is same for epoxy, steel, and HM-CFRP. Traction separation properties are assigned to epoxy material which is modeled as a film material with a thickness of $0.1 \mathrm{~mm}$.

HMCFRP is defined by the Brittle-cracking mathematical model because it is exposed to higher tensile stresses and will not yield after rupture. In this analysis, the material was modeled as linear-elastic up to its maximum tensile stress capacity, beyond which it loses all load-carrying capacity. It can be very hard to identify this postcracking phase experimentally because it occurs so quickly. This study modeled postcracking as the $1 \%$ strain level using the linear model (Table 2(d)). Shear retention was also accounted for to consider variations in post-cracked shear stiffness. The fiber material was modeled as 8-node solid elements.

The model developed for the experimental test beam using the modeling details provided above is depicted in Figure 3. The boundary conditions and the loading scenario are modeled as they were in the actual experiment. The aspect ratio of one is ensured when constructing finite elements. Also the mesh sensitivity analysis is carried out by seeding the model with $5 \mathrm{~mm}, 10 \mathrm{~mm}, 20 \mathrm{~mm}$, and $40 \mathrm{~mm}$ sized finite elements, respectively. The model is found to be sensitive to mesh density thus $10 \mathrm{~mm}$ mesh size is selected for further studies reported herein.

The results obtained from the numerical model analyses were compared with the actual experimental results to validate the accuracy of the models. The comparisons of the beam's behavior under loading are shown in Figure 4, and the maximum load-carrying capacities obtained from the experiments and finite element modeling (FEM) analysis are listed in Table 3 for both strengthened and unstrengthened beams. 


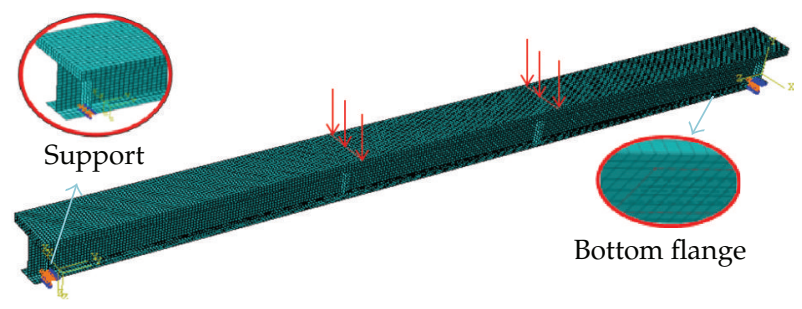

Figure 3: Finite element model of experimental specimen.

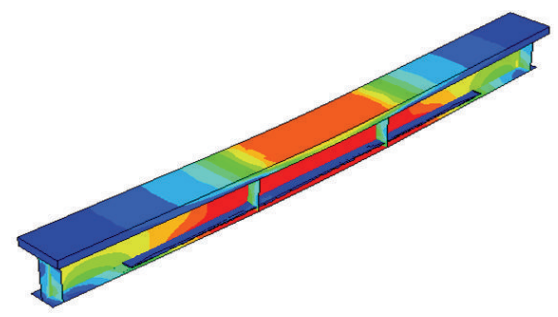

(a)

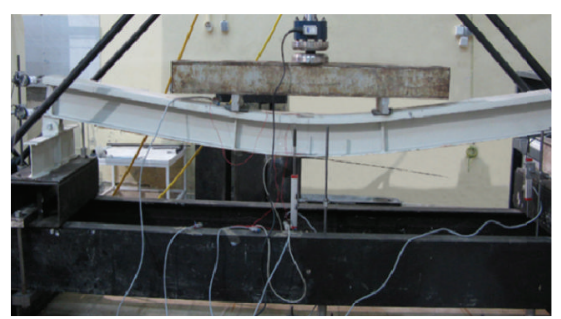

(b)

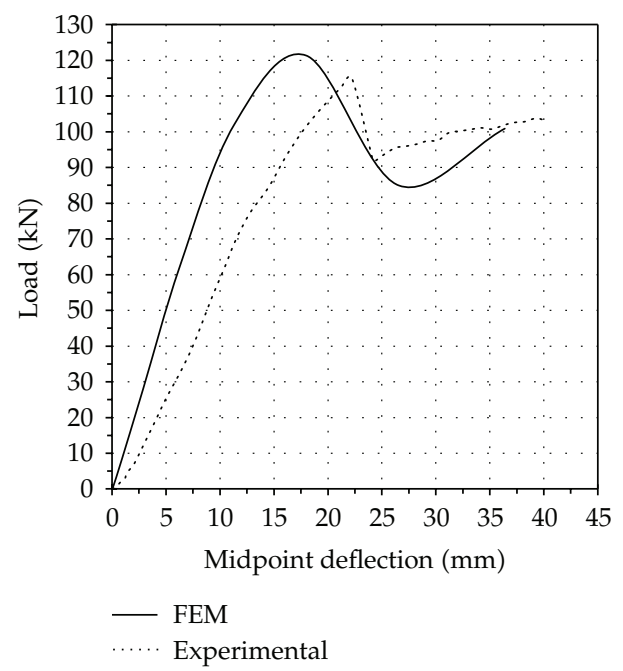

(c) Comparison of numerical and experimental test results

Figure 4: Numerical verification of experimental results.

Table 3: Comparison of strengthened and reference beams during numerical analysis and experimental testing.

\begin{tabular}{llccc}
\hline & & Experiment & FEM & \% Difference \\
\hline \multirow{2}{*}{ Reference beam } & Max load $(\mathrm{kN})$ & 83 & 84 & 1.2 \\
& Max moment $(\mathrm{kN}-\mathrm{m})$ & 43.6 & 44.13 & 1.2 \\
\multirow{2}{*}{ Strengthened beam } & Max load $(\mathrm{kN})$ & 115.4 & 121 & 4.85 \\
& Max moment $(\mathrm{kN}-\mathrm{m})$ & 60.58 & 63.52 & 4.85 \\
\hline
\end{tabular}


The experimental results and numerical models for the unstrengthened beam show a difference of $1.2 \%$ in maximum load-carrying capacity. This difference increased to $4.85 \%$ for strengthened beams. Both of these values are within acceptable ranges. The higher error of the strengthened beams can be explained by the complex behavior of the interface element. The difference between deflection points corresponding to the maximum loads is approximately $24 \%$ and could be explained as a consequence of the approximations used in the material models and ignoring geometric imperfections for the numerical model. Hence, the material is more inclined to display rigid behavior in the numerical model. Because the goal of this study was to determine the increase in load-carrying capacity during the strengthening process, the difference in the deflection estimates can be considered negligible for parametric studies.

The most important result obtained from the numerical model is the rupture behavior of the HMCFRP and the initiation of the postrupture load bearing of the steel. Analysis of the figures shows a sudden drop in the specimen's load-carrying ability right after the peak point, which corresponds to the rupture of the HMCFRP. When this rupture occurs, the steel continues to carry load because it has undergone a strain hardening process. This experimentally observed behavior was also achieved using numerical analysis under similar conditions.

\section{Parametric Study}

Upon further development and testing, the experimentally validated numerical models provided insight into the specific questions asked at the beginning of the study, including the maximum quantity of HMCFRP that can be used, failure modes, and the relationship between HMCFRP usage and load-carrying capacity increases. A total of 149 models for numerical specimens were developed using various quantities of HMCFRP with 7 commonly used industry-wide IPE profile sections of different lengths. Table 4 shows the properties of the numerical specimens. Based on the study reported by Aktas et al. [16], the development lengths were set at 900, 1800, and $3600 \mathrm{~mm}$ for beams with lengths of 3000, 6000, and $12000 \mathrm{~mm}$, respectively. Variations in the specimens' load-carrying capacities were investigated by using various quantities of HMCFRP.

\subsection{Parametric Study Results and Discussion}

Individual load deflection figures were created for all numerical specimens after the parametric study was completed. The results are discussed for an example in more detail, while the results for all beams are tabulated.

To illustrate the results, the load deflection figures obtained for an IPE 270 profile with different HMCFRP ratios are shown in Figure 5. The percentage increases in loadcarrying capacity calculated with respect to the reference beam are compared and plotted in the figure. Figure 6 summarizes the relation between HMCFRP usage and the percentage increase in capacity calculated for a single beam. As shown in Figure 6, the maximum increase in load-carrying capacity for an IPE 270 was determined for the beam strengthened with $8.9 \%$ HMCFRP. The increase in capacity began to decline when the HMCFRP usage reached $11.8 \%$.

To explain this behavior, one must analyze the stresses of all materials at midspan where the maximum stresses have been observed. Figure 7 shows the stress contour of each material at midspan for the IPE 270 beam strengthened with $11.8 \%$ HMCFRP.

Investigation of the stress contour maps for the beam strengthened with $11.8 \%$ HMCFRP shows that the steel did not yield around the boundary of the elastic region (a), 


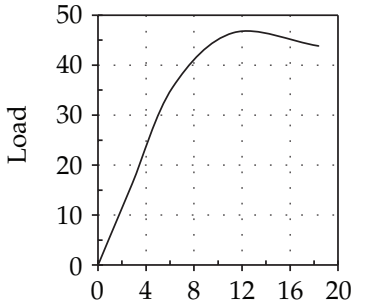

Midpoint deflection (mm) - \%3.5 HM-CFRP Increase in load capacity: $18 \%$

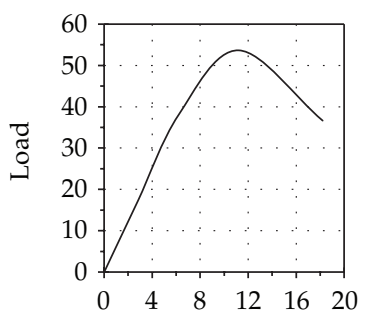

Midpoint deflection ( $\mathrm{mm}$ ) \%6.1 HM-CFRP Increase in load capacity: $36 \%$

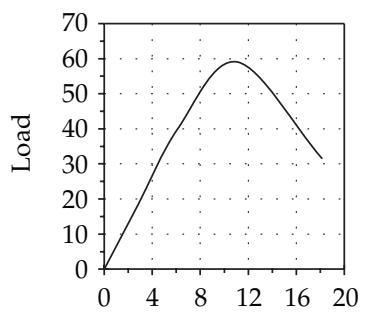

Midpoint deflection (mm) — 8.9 HM-CFRP

Increase in load capacity: $51 \%$

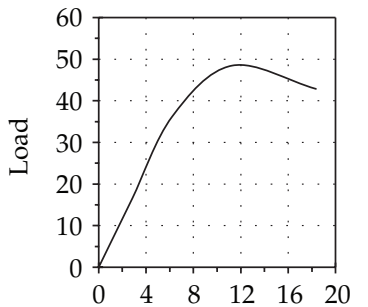

Midpoint deflection (mm) - \% 4.2 HM-CFRP Increase in load capacity: $23 \%$

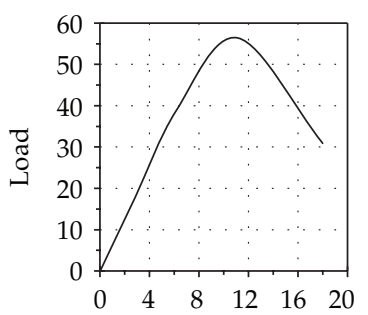

Midpoint deflection (mm) \%7.3 HM-CFRP Increase in load capacity: $44 \%$

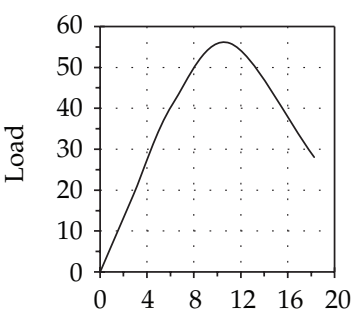

Midpoint deflection ( $\mathrm{mm}$ ) — $\% 9.7$ HM-CFRP Increase in load capacity: $42 \%$
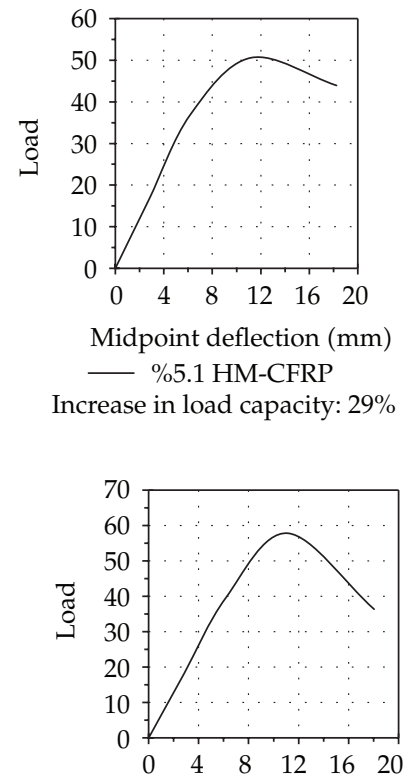

Midpoint deflection (mm) \%8.1 HM-CFRP Increase in load capacity: $47 \%$

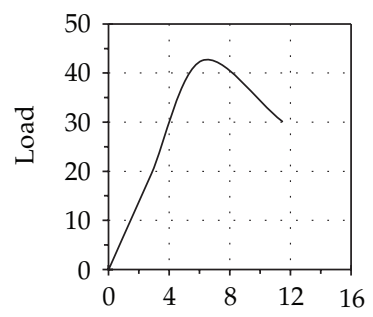

Midpoint deflection ( $\mathrm{mm}$ ) $\% 11.8$ HM-CFRP Increase in load capacity: $8 \%$

Figure 5: Load deflection plots for IPE 270, $L=3000 \mathrm{~mm}$.

while the epoxy and HMCFRP seemed to approach their respective maximum stress levels. The region following the ultimate capacity (b) shows the point where epoxy broke along with the associated decay in the stress of the HMCFRP. (b) was also the point at which the steel stresses started to increase. This behavior can also be explained by the debonding of the HMCFRP without having reached its maximum deformation. In other words, although the HMCFRP stress level did not achieve failure, the epoxy material reached its ultimate capacity.

The maximum HMCFRP quantities are listed for each numerical specimen in Table 5 individually based on the procedures explained in Figures 5 and 6.

The values in the table above show a declining trend in the maximum HMCFRP usage ratio as the beam section area increases. This is an expected outcome because there is a higher chance of interface element failure due to extra loading on the HMCFRP installation. 


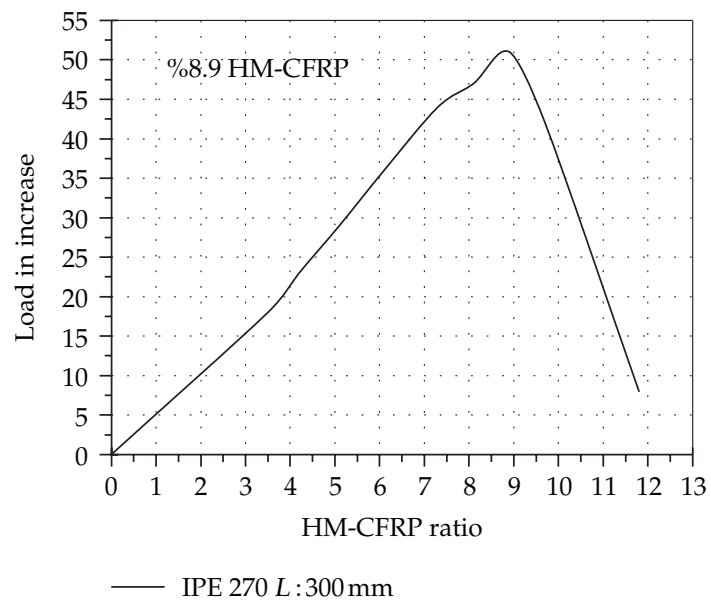

Figure 6: Relationship between HMCFRP ratio and load percentage increase.

Table 4: Numerical specimens in the parametric study.

\begin{tabular}{|c|c|c|c|c|}
\hline Beam section & $\begin{array}{l}\text { Beam length } \\
(\mathrm{mm})\end{array}$ & $\begin{array}{l}\text { Development length } \\
(\mathrm{mm})\end{array}$ & $\begin{array}{l}\text { HMCFRP length } \\
(\mathrm{mm})\end{array}$ & Area $_{\mathrm{HM}-\mathrm{CFRP}} /$ Area $_{\text {Section }}$ \\
\hline IPE 120 & 3000 & 900 & 2600 & $3.5-16.3$ \\
\hline IPE 160 & 3000 & 900 & 2600 & $3.5-17.5$ \\
\hline \multirow{2}{*}{ IPE 220} & 3000 & 900 & 2600 & $3.5-18.0$ \\
\hline & 6000 & 1800 & 5200 & $3.5-11.7$ \\
\hline \multirow{2}{*}{ IPE 270} & 3000 & 900 & 2600 & $3.5-11.8$ \\
\hline & 6000 & 1800 & 5200 & $3.5-22.4$ \\
\hline IPE 330 & 6000 & 900 & 5200 & $3.5-22.4$ \\
\hline \multirow{2}{*}{ IPE 400} & 6000 & 900 & 5200 & $3.5-14.1$ \\
\hline & 12000 & 1800 & 10400 & $1.7-7.10$ \\
\hline \multirow{2}{*}{ IPE 500} & 6000 & 900 & 5200 & $3.5-11.7$ \\
\hline & 12000 & 1800 & 10400 & $1.8-8.80$ \\
\hline
\end{tabular}

Table 5: Maximum HMCFRP ratio for each beam.

\begin{tabular}{lcccc}
\hline Section & Beam length $(\mathrm{mm})$ & HMCFRP ratio $(\%)$ & Increase in $P_{u}(\%)$ & Number of specimens \\
\hline IPE 120 & 3000 & 14 & 97 & 16 \\
IPE 160 & 3000 & 11 & 67 & 17 \\
IPE 220 & 3000 & 15 & 69 & 15 \\
& 6000 & 8 & 109 & 12 \\
IPE 270 & 3000 & 8.9 & 51 & 9 \\
IPE 330 & 6000 & 7.3 & 54 & 15 \\
IPE 400 & 6000 & 8.8 & 61 & 16 \\
& 6000 & 6.7 & 31 & 13 \\
IPE 500 & 12000 & 3.5 & 62 & 9 \\
& 6000 & 5.1 & 39 & 12 \\
\hline
\end{tabular}




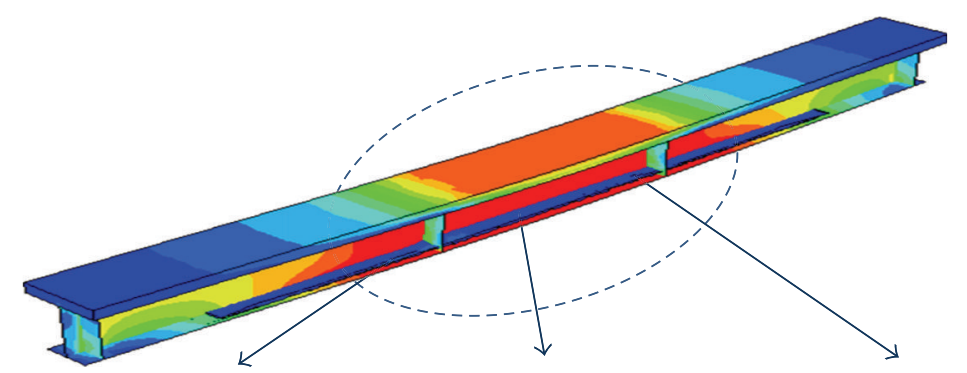

EPOXY

$S$, Mises

(Avg: 75\%)
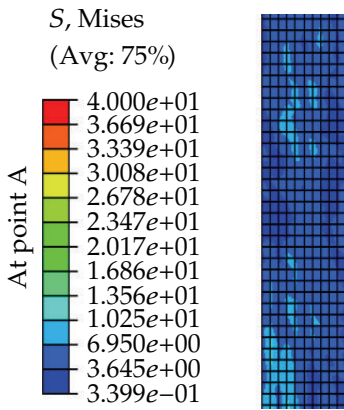

S, S22

Multiple section point (Avg:75\%)
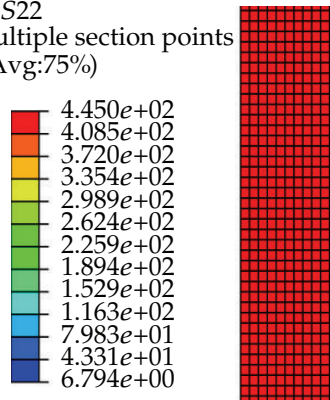

Steel section

HMCFRP

$S, S 22$ Multiple section points (Avg: 75\%)

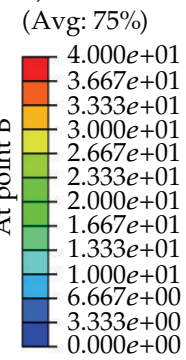

$S$, Mises

$3.667 e+01$

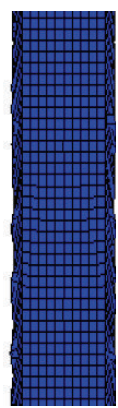

$4.450 e+02$
$3.803 e+02$

$3.803 e+02$

$3.156 e+02$
$2.509 e+02$

- $2.509 e+02$

$1.215 e+02$

- $5.675 e+01$

$-7.267 e+01$

$-1.374 e+02$

$-2.021 e+02$

$-2.668 e+02$

$-3.315 e+02$

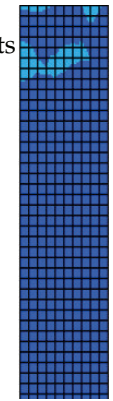

S, Mises

Multiple section points

(Avg: 75\%)

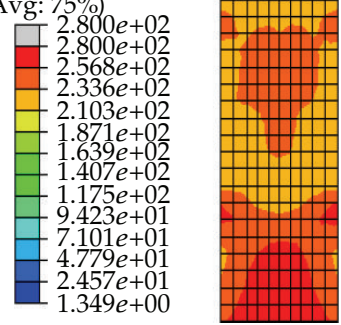

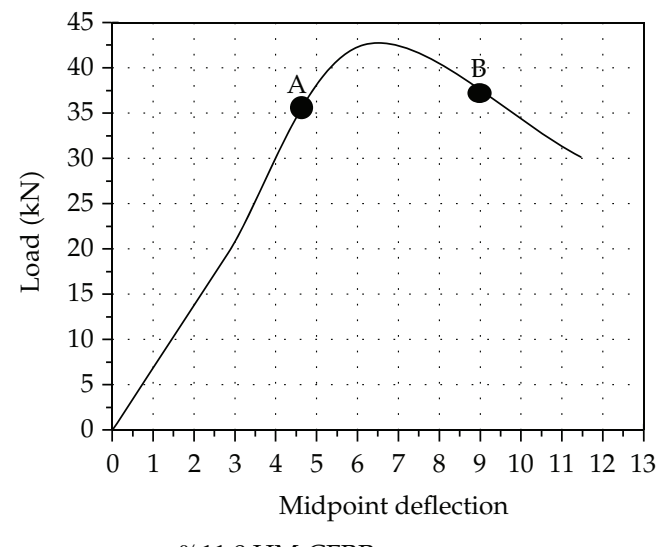

Figure 7: Stress contour of each material at beam midspan. 


\section{Conclusions}

The load-carrying capacity of steel beams can be increased up to approximately $100 \%$ by strengthening the beams with HMCFRP. The ability to increase load-carrying capacity without increasing the structure's dead weight is a significant improvement over previous strengthening techniques. This improvement also reduces deformations due to dead weight loading. The amount of HMCFRP used in such a scenario affects the behavior of the beam significantly. To achieve effective strengthening, HMCFRP must reach high stress levels close to rupture without debonding at the epoxy interface. It is important to prevent such cases from occurring. Although greater HMCFRP usage is expected to progressively increase the load-carrying capacity, it has been shown that this is not generally the case. Instead, there is an upper limit to the quantity of HMCFRP that can be used. The most effective method of determining this upper limit is to develop a nonlinear finite element model of the beam type and analyze this model. This study discussed a methodology for developing such finite element models in detail. Using this methodology, steel beams can be repaired and strengthened when environmental effects such as corrosion and ever-increasing load requirements necessitate the addition of material to a structure.

\section{References}

[1] D. Schnerch and S. Rizkalla, "Strengthening of scaled steel-concrete composite girders and steel monopole towers with CFRP," in Proceedings of the 2nd International Conference on FRP Composites in Civil Engineering (CICE '04), Adelaide, Australia, December 2004.

[2] O. Benjeddou, M. B. Ouezdou, and A. Bedday, "Damaged RC beams repaired by bonding of CFRP laminates," Construction and Building Materials, vol. 21, no. 6, pp. 1301-1310, 2007.

[3] A. Sharif, G. J. Al-Sulaimani, I. A. Basunbul, M. H. Baluch, and B. N. Ghaleb, "Strengthening of initially loaded reinforced concrete beams using FRP plates," ACI Structural Journal, vol. 91, no. 2, pp. 160-168, 1994.

[4] M. Arduini and A. Nanni, "Behavior of precracked RC beams strengthened with carbon FRP sheets," Journal of Composites for Construction, vol. 1, no. 2, pp. 63-70, 1997.

[5] D. S. Lunn and S. H. Rizkalla, "Strengthening of infill masonry walls with FRP materials," Journal of Composites for Construction, vol. 15, no. 2, pp. 206-214, 2011.

[6] A. H. Al-Saidy, F. W. Klaiber, and T. J. Wipf, "Repair of steel composite beams with carbon fiberreinforced polymer plates," Journal of Composites for Construction, vol. 8, no. 2, pp. 163-172, 2004.

[7] J. A. García, A. Chiminelli, B. García, M. Lizaranzu, and M. A. Jiménez, "Characterization and material model definition of toughened adhesives for finite element analysis," International Journal of Adhesion and Adhesives, vol. 31, no. 4, pp. 182-192, 2011.

[8] M. Tavakkolizadeh and H. Saadatmanesh, "Strengthening of steel-concrete composite girders using carbon fiber reinforced polymers sheets," Journal of Structural Engineering, vol. 129, no. 1, pp. 30-40, 2003.

[9] S. Rizkalla, M. Dawood, and D. Schnerch, "Development of a carbon fiber reinforced polymer system for strengthening steel structures," Composites A, vol. 39, no. 2, pp. 388-397, 2008.

[10] M. Dawood and S. Rizkalla, "Bond and splice behavior of high modulus CFRP materials boned to steel structures," in Proceedings of the 3rd International Conference on FRP Composites in Civil Engineering Miami, 2006.

[11] D. Schnerch, K. Stanford, E. A. Sumner, and S. Rizkalla, "Bond behavior of CFRP strengthened steel bridges and structures," in Proceeding of International Symposium on Bond Behavior of FRP in structures, 2005.

[12] D. Schnerch, M. Dawood, S. Rizkalla, and E. Sumner, "Proposed design guidelines for strengthening of steel bridges with FRP materials," Construction and Building Materials, vol. 21, no. 5, pp. 1001-1010, 2007.

[13] R. Sen, L. Liby, and G. Mullins, "Strengthening steel bridge sections using CFRP laminates," Composites B, vol. 32, no. 4, pp. 309-322, 2001. 
[14] T. Chen, X. Gu, and X. Zhao, "Fatigue behavior of CFRP repair non-load carrying cruciform welded Joint," in Proceedings of the 5th International Conference on FRP Composites in Civil Engineering, pp. 907910, 2010.

[15] T. Chen, Q. Q. Yu, X. L. Gu, and X. L. Zhao, "Study on fatigue behavior of strengthened non-loadcarrying cruciform welded joints using carbon fiber sheets," International Journal of Structural Stability and Dynamics, vol. 12, no. 1, pp. 179-194, 2012.

[16] M. Aktas and E. Agcakoca, "Defining development length Of HM-CFRP in composite I-section strengthened with HM-CFRP," New World Sciences Academy, vol. 7, no. 2, pp. 47-59, 2012.

[17] C. Cattani, J. J. Rushchitsky, and S. V. Sinchilo, "Physical constants for one type of nonlinearly elastic fibrous micro-and nanocomposites with hard and soft nonlinearities," International Applied Mechanics, vol. 41, no. 12, pp. 1368-1377, 2005.

[18] M. Aktas and C. J. Earls, "Minor axis moment-thrust response behavior in steel I-shaped members," Journal of Structural Engineering, vol. 132, no. 7, pp. 1079-1086, 2006. 


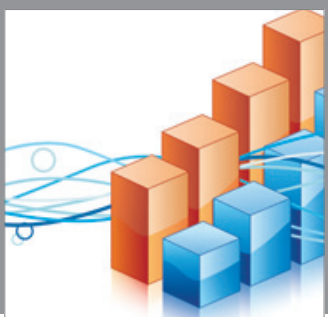

Advances in

Operations Research

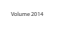

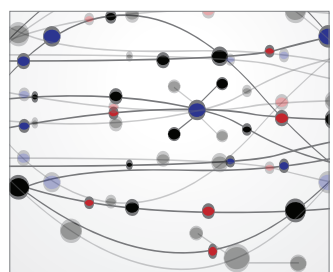

\section{The Scientific} World Journal
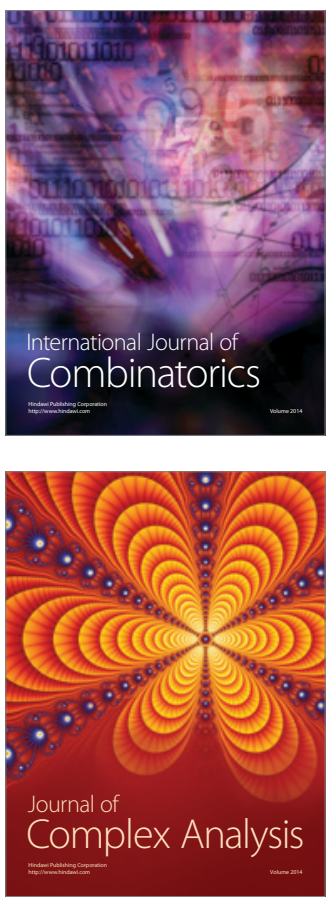

International Journal of

Mathematics and

Mathematical

Sciences
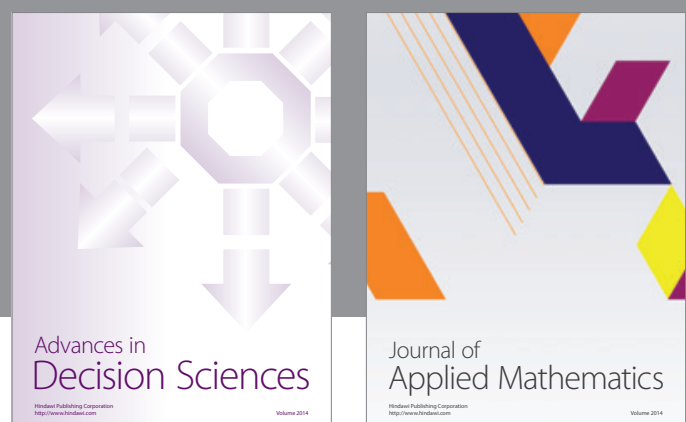

Journal of

Applied Mathematics
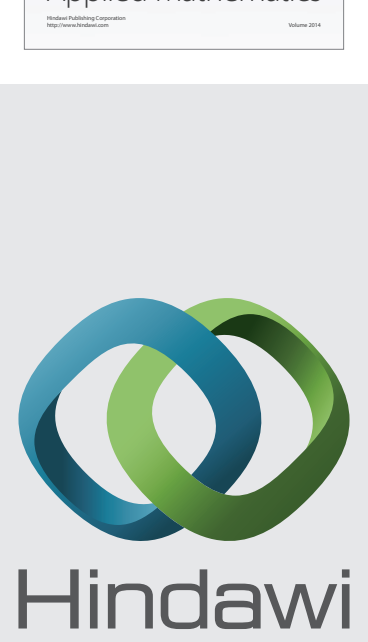

Submit your manuscripts at http://www.hindawi.com
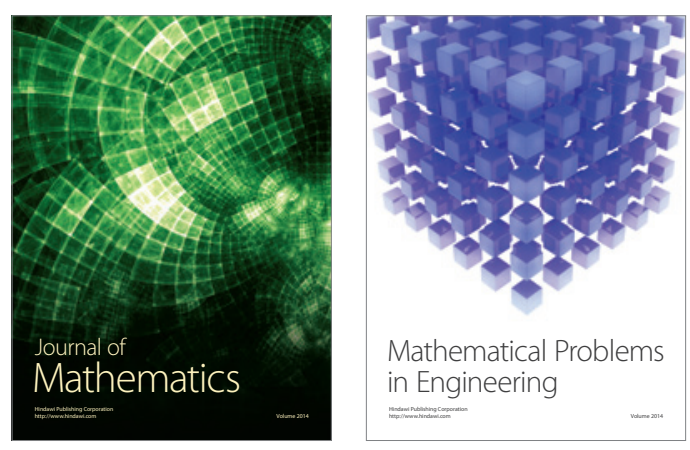

Mathematical Problems in Engineering
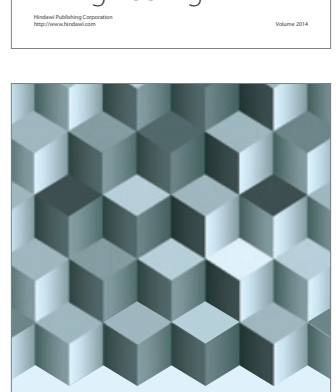

Journal of

Function Spaces
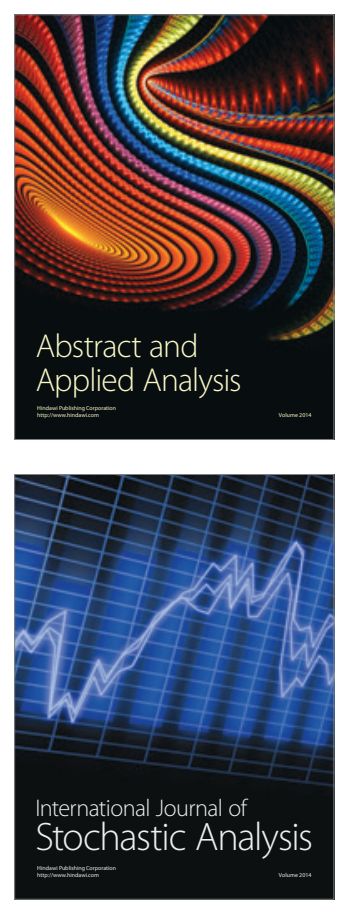

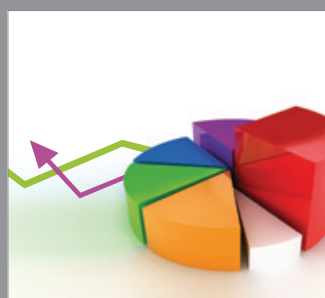

ournal of

Probability and Statistics

Promensencen
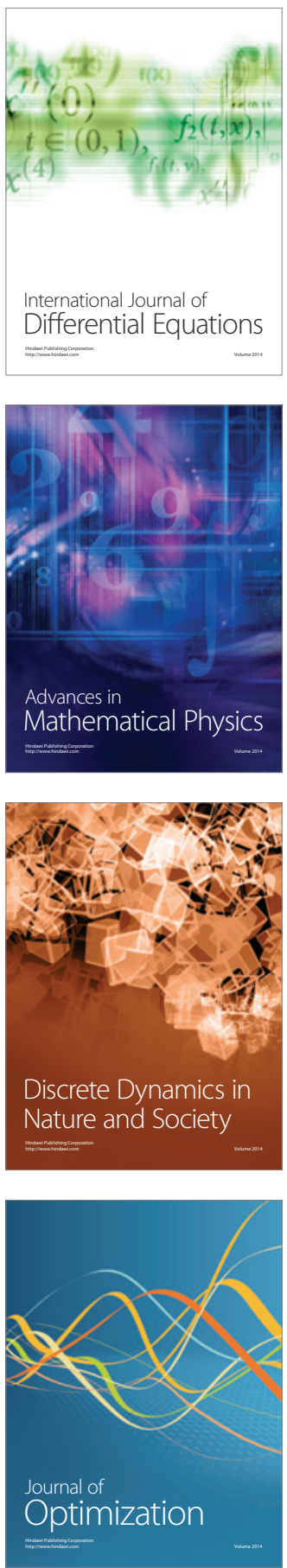